\title{
The effects of age on the neural correlates of successful episodic retrieval: An ERP study
}

\author{
JUAN LI \\ Chinese Academy of Sciences, Beijing, China \\ and \\ ALEXA M. MORCOM and MICHAEL D. RUGG \\ University College London, London, England
}

\begin{abstract}
The neural correlates of successful episodic retrieval (recollection), as reflected in event-related potentials (ERPs), were investigated in young (ca. 20 years; $n=18$ ) and older (ca. 70 years; $n=16$ ) healthy individuals. Subjects classified a series of pictures according to whether each item was new or had been encountered at study in the context of an animacy or a size judgment task. By manipulating the number of times items were presented for study, subsets of test items were formed for which source accuracy did not differ according to age. Relative to ERPs elicited by unstudied pictures, ERPs elicited by items attracting equivalent levels of source accuracy showed marked age-related differences. Those from younger subjects demonstrated the positive-going left parietal and right frontal old/new effects described in several previous studies of source memory. By contrast, analogous ERPs from older subjects contained a large left-lateralized negative effect that overshadowed the positive-going effects evident in the young. No age-related differences in either parietal or frontal ERP old/new effects were detected at electrode sites overlying the right hemisphere. It is possible that the age-related ERP differences observed in this task primarily reflect the use of different kinds of information as a basis for source judgments.
\end{abstract}

Episodic memory-memory for unique events and their contexts - appears to be more vulnerable to aging than are other forms of memory, such as familiarity-based recognition (Yonelinas, 2001) or implicit memory as manifest in priming effects (LaVoie \& Light, 1994). It is uncertain to what extent age-related impairment in episodic memory is due to changes in the capacity to encode new information (e.g., Craik \& Rabinowitz, 1985; Glisky, Rubin, \& Davidson, 2001; Perfect, Williams, \& AndertonBrown, 1995), as opposed to changes in retrieval processes (e.g., Burke \& Light, 1981; Craik \& McDowd, 1987).

The focus of the present article is on the effects of age on the neural correlates of successful episodic retrieval (often referred to as recollection). Recollection of a prior event is a constructive process that involves interaction between a retrieval cue (either self-generated or provided by the environment) and the memory representation of the episode (Tulving, 1983). Successful recollection requires engagement of a number of distinct cognitive operations (Rugg \& Wilding, 2000; Rugg \& Yonelinas, 2003) that support such functions as the representation of the retrieval goal, appropriately directed cue processing, the recovery and representation of retrieved information,

This research was supported by the Wellcome Trust, by a Royal Society China Research Fellowship, and by Chinese National Science Foundation Grant 30100055 awarded to J.L. Correspondence concerning this article should be addressed to M. D. Rugg, Center for the Neurobiology of Learning and Memory, University of California, Irvine, CA 92697-3800 (e-mail:mrugg@uci.edu). and its subsequent evaluation in service of the retrieval goal. Any one or more of these functions might be affected by aging. In the present study, we investigated the effects of age on the neural correlates of processes supporting the recovery and evaluation of episodic information as reflected in scalp event-related brain potentials (ERPs; see Morcom \& Rugg, 2004, for an example of an ERP study of the effects of age on cue processing).

This is not the first study of age effects on the ERP correlates of successful memory; in several studies, the effects of age on ERPs elicited during tests of recognition memory have been investigated (e.g., Friedman, Berman, \& Hamberger, 1993; Rugg, Mark, Gilchrist, \& Roberts, 1997; Swick \& Knight, 1997; see Friedman, 2000, for a review). It is generally agreed, however, that successful recognition memory is not synonymous with successful episodic retrieval. Correct recognition judgments can be based not only on the recollection of a study item (recollection), but also on a form of memory known as familiarity - an acontextual sense of prior occurrence that is functionally and neurally distinct from recollection (Yonelinas, 2001). Unless the test procedure permits segregation of successful recognition judgments according to whether they were accompanied by recollection, findings from studies of recognition memory are of limited utility for investigating the effects of age on processes supporting episodic memory. Specifically, age differences in the neural correlates of successful recognition may merely reflect differences in the proportion of correct judgments accompanied by recollection, rather than differences in recollection-related 
processes per se (see Rugg \& Morcom, in press, for further discussion of this and related issues).

Previous research has identified two ERP effects that appear to be associated quite closely with recollection (for reviews, see Friedman \& Johnson, 2000, and Rugg $\&$ Allan, 2000). Both of these effects take the form of positive-going deflections in the waveforms elicited by recollected items, relative to ERPs elicited by items correctly judged as new. The left parietal old/new effect onsets around 400-500 msec poststimulus, persists for about $400 \mathrm{msec}$, and, as its name suggests, is maximal over the left parietal scalp. It has been proposed that the effect is a neural correlate of the retrieval and representation of episodic information (e.g., Wilding \& Rugg, 1996). A second effect, the right frontal old/new effect, onsets somewhat later and exhibits a more sustained time course $(>1 \mathrm{sec})$, with a maximum over the right frontal scalp. This effect was originally held to reflect monitoring and evaluative operations carried out on the products of successful episodic retrieval (Wilding \& Rugg, 1996). More recently, this proposal has been modified to suggest that the right frontal effect reflects monitoring of the outcome of a retrieval attempt, whether successful or not, in the service of a behavioral goal. By this account, successful recollection is neither necessary nor sufficient to elicit the effect. The effect will be elicited, however, in circumstances in which the appropriate behavioral response depends on evaluation of the content of recollected information, as is the case in tests of source memory (Rugg, Otten, \& Henson, 2002).

To our knowledge, there are only three published studies of age-related differences in ERP correlates of retrieval in which memory test trials associated specifically with recollection were identified. Trott, Friedman, Ritter, and Fabiani (1997; see also Trott, Friedman, Ritter, Fabiani, $\&$ Snodgrass, 1999, for a fuller description of the same study) presented subjects at study with two lists of sentences, each terminated by a word that had to be memorized in anticipation of a subsequent test. At test, the subjects judged items as old or new. For old items, they then both made a remember/know judgment (Tulving, 1985) and judged whether the item belonged to the first or the second study list. Trials associated with either a remember response or a correct source judgment are likely to have been associated with recollection, the former on the basis of subjective report and the latter on the basis of objective evidence for the retrieval of study context. Regardless of which criterion was applied, both young and older subjects demonstrated robust left parietal old/new effects that did not differ in magnitude. By contrast, whereas the ERPs of the young subjects also exhibited a large right frontal effect, this effect was absent in the older subjects' waveforms. Trott et al. (1997; Trott et al., 1999 ) interpreted their findings as evidence for a relatively intact capacity for automatic detection of prior occurrence in their older subjects, along with impairment in the strategic, evaluative processes reflected by the right frontal effect. They argued that their findings were con- sistent with the proposal that a key factor underpinning age-related decline in episodic memory is impairment in cognitive operations supported specifically by the prefrontal cortex (e.g., West, 1996). These findings were replicated by Wegesin, Friedman, Varughese, and Stern (2002). This study employed essentially the same procedures as its predecessor but was modified to improve the source memory performance of the older subjects, which had been barely above chance in the original study.

Importantly, in both the aforementioned studies, an additional old/new effect was also evident. Unlike the left parietal and right frontal effects, this third effect was negative going. It was maximal over the centro-parietal scalp and occupied approximately the same latency range as the right frontal effect. Furthermore, it was greater in magnitude in the older subjects' ERPs, raising the possibility that overlap between it and the frontal effect may have played a role in the frontally distributed age-related differences apparent in the two studies. We will return to this possibility in the discussion.

A third study of the influence of age on the ERP correlates of episodic retrieval was reported by Mark and Rugg (1998). The study task involved auditorily presented words, with the requirement to perform one of two encoding tasks, depending on the gender of the speaker. In all the test blocks, subjects first judged items (now presented visually) as old or new. In different blocks, items judged old were then either subjected to a source judgment (male vs. female voice) or given a remember/know judgment. Recollected items were defined as those attracting either correct source judgments or correct remember responses. No ERP differences were found according to how recollection was defined (cf. Trott et al., 1997; Trott et al., 1999), and neither left parietal nor right frontal old/new effects differed according to age (the only age-related difference was a relatively delayed onset, ca. $100 \mathrm{msec}$, in the older group's left parietal effect). Thus, consistent with the findings of Trott et al. (1997; Trott et al., 1999) and Wegesin et al. (2002), there was no evidence that age influenced retrieval processing as manifest by the left parietal old/new effect. In contrast with these findings, however, there was also no evidence of an age-related impairment in the monitoring/evaluation operations held to be supported by the prefrontal cortex. Perhaps significantly, nor was there much sign of the negative-going old/new effect that differentiated young and older subjects' ERPs in the other two studies.

A feature common to all three of the studies above was that older subjects' source memory performance was lower than that of the young (the difference in source accuracy, measured as proportion of correct source judgments/ proportion of items correctly judged old, was .12, .28, and .17, in Trott et al., 1997; Trott et al., 1999; Wegesin et al., 2002; and Mark \& Rugg, 1998, respectively). These differences are, of course, to be expected given the vulnerability of episodic memory to aging. They raise the possibility, however, that the findings from these studies may, to some extent, represent a confounding of age effects 
with performance-related factors. For example, in response to the relatively greater difficulty of the retrieval task, older subjects may have devoted more resources to cue processing and had less to spare for such operations as postretrieval monitoring. Furthermore, as source memory performance declines, the proportion of correct source judgments due to lucky guesses increases, leading to greater dilution of the neural correlates of recollection (Rugg \& Morcom, in press). Thus, when, as in these studies, young subjects outperform older individuals, comparison of the relative magnitudes of ERP recollection effects from the two groups is likely to favor the young. The aim of the present study was to investigate the effects of age on the ERP correlates of successful episodic retrieval while avoiding these and related difficulties. This was accomplished, first, by employing perceptually rich pictorial material, inherently more memorable than the verbal items used previously, and second, by manipulating the encoding task across the two subject groups to create a set of test items for which source memory was at comparable levels. In addition, the experimental design incorporated a manipulation of difficulty so that the effects of this variable on the ERP old/new effects of young and older subjects could be directly assessed.

\section{METHOD}

\begin{abstract}
Subjects
Twenty-seven healthy adults between 18-34 years of age and 21 between $63-75$ years participated. The young subjects were undergraduate and graduate students and professionals, and the older subjects were retired professionals. Data from 9 young and 5 older subjects were rejected because there were too few $(<16)$ artifactfree trials in one or more critical experimental conditions. Of the 18 young and 16 older subjects contributing data, all reported that they were in good health and right-handed. All were free from central nervous system-active medication. Informed consent was obtained prior to participation, and the experimental procedures were approved by the Joint University College London (UCL) and UCLH Committees on the Ethics of Human Research and by the Institute of Neurology and National Hospital for Neurology and Neurosurgery Joint Research Ethics Committee.
\end{abstract}

\section{Neuropsychological Tests}

All the subjects completed a battery of standardized neuropsychological tests targeting certain cognitive functions that show a decline with age and others that are generally found to be spared. The tests were administered in a separate 1.5 -h session. The older subjects were first given the Folstein Mini-Mental State test (Folstein, Folstein, \& McHugh, 1975) as a screening measure, and a minimum score of 26/30 was required for inclusion in the study (Lezak, 1995). The test battery comprised the National Adult Reading Test (NART; Nelson, 1982), the Warrington-McKenna Graded Naming test (see Clegg \& Warrington, 2000), the Digit Span Forward and Verbal Paired Associates tests from WMS-R (Wechsler, 1987), the Adult Memory and Information Processing Battery short story recall test (Coughlan \& Hollows, 1985), the Raven's Advanced Progressive Matrices II (Raven, Raven, \& Court, 1994), and the FAS verbal fluency test (Lezak, 1995).

\section{Stimuli}

Two hundred forty color pictures of objects served as critical stimuli. For each matched pair of one young and one older subject, six lists of 40 pictures each were formed using a random selection of items, with the constraint that the distribution of encoding-taskrelated characteristics (i.e., size and animacy) would be the same in each. Four lists were used as studied items, two for size judgments and two for animacy decisions. The other two lists were used as new items during test. Each study block was formed by pseudorandomizing the order of items so that the same decision task would not occur on more than three consecutive trials. To match the performance between the age groups, source memory difficulty was manipulated by varying how often the items were presented at study. Pilot work indicated that source memory accuracy was equivalent in the two age groups when items were studied twice by the young and three times by the older subjects. Therefore, items from one size decision list and one animacy decision list were presented once for both age groups (hard condition), and those from the other two lists were repeated either two or three times according to age group (easy condition). Repeated and nonrepeated items were intermixed in three or four study blocks for young and older subjects, respectively, each block comprising 80 critical items plus two fillers at the beginning. An additional 16 pictures formed two practice lists for the study task.

For test, a pseudorandom trial sequence was generated with the four studied lists and two new lists, plus 80 fixation-only trials on which no stimulus was to be shown, ${ }^{1}$ so that no more than three events of a given type (studied, unstudied, or fixation) would occur in a row. This test sequence was divided into four blocks of 80 trials, and two fillers were added to the beginning of each block. Eight additional unstudied items were combined with the 16 studied items to create two practice lists for the test task.

\section{Procedure}

Following electrode application (see below), the subjects were seated in a sound-attenuated recording booth $90 \mathrm{~cm}$ from a display monitor. Before beginning the experiment proper, two brief study-test practice cycles were administered. The study task was then completed, followed after a 2- to 3-min interval by the source memory test.

All the pictures were presented within a $3.8 \times 3.8 \mathrm{~cm}$ white frame in the center of a black monitor screen. This frame subtended a visual angle of $2.4^{\circ} \times 2.4^{\circ}$. Pictures were shown in color, and cue words (see below) were shown in a white upper- and lowercase Helvetica 36-point font.

In the study phase, the stimuli were displayed for $1.5 \mathrm{sec}$. Each was preceded by the presentation of a cue word for $1.5 \mathrm{sec}$. When the cue was "Size?" the task was to decide whether, in real life, the object would fit inside a shoebox. When the cue was "Living?" it was to decide whether the object was a living or a nonliving thing. All the responses were verbal, and the subjects were instructed first to report their judgment of an item and then to name the object in the picture. These responses were monitored and recorded by the experimenter to check that cues were correctly processed and the appropriate decisions made and that items were seen clearly enough to be identified. Task timing was self-paced, so that the presentation of the cue for the next trial was triggered when the subject pressed a button on the response box. Short rests were given between blocks. The subjects were informed that their memory both for the pictures and for the corresponding decisions would be tested subsequently.

During the test phase, there was a fixation + sign in the center of the screen at all times, which was white in color between stimulus presentations. The color of the fixation sign changed to red $1,200 \mathrm{msec}$ before the onset of each picture stimulus. The red fixation sign then remained on screen with the picture. Each stimulus was presented for $500 \mathrm{msec}$, and the intertrial interval was $5 \mathrm{sec}$. Since some trials were fixation only, this meant that the stimulus onset asynchrony experienced by the subjects was between 5 and $15 \mathrm{sec}$. The subjects judged whether they had previously seen a picture and made a size decision — whether they had previously seen a picture and 
made a living-nonliving decision or whether the picture was newand responded by pressing buttons under the middle and index fingers of one hand and the index finger of the other hand, respectively. Assignment of hands to responses were counterbalanced across subjects. The subjects were instructed to respond as quickly and accurately as possible, and to respond new if unsure whether an item was old or new. They were also requested to relax, to avoid making eye movements other than blinks, and to maintain fixation on the + sign at all times. Three short rest breaks were given after every 82 items. Following the test phase, the new items were re-presented to the subjects at a self-paced rate so as to identify any items that had not been perceived correctly during the experiment.

\section{ERP Recording}

EEGs were recorded with silver/silver chloride electrodes from 31 sites, 29 of which were embedded in an elastic cap (a subset of the "montage 10" provided by the manufacturer; see http://www. easycap.de/easycap/english/schemae.htm and Figure 1). The other two electrodes were placed on the mastoid processes bilaterally. Vertical and horizontal EOGs were recorded from bipolar electrode pairs placed above and below the right eye and on the outer canthi of both eyes. EEG recordings were made with reference to a mid-frontal electrode $(\mathrm{Fz})$ and were rereferenced off line to linked mastoids. EEGs and EOGs were amplified with a bandwidth of $0.03-35 \mathrm{~Hz}(3-\mathrm{dB}$ points) and digitized at $125 \mathrm{~Hz}$. Prior to averaging, the EEG was digitally smoothed ( $3 \mathrm{~dB}$ down at $19.4 \mathrm{~Hz}$ ), and a correction procedure was applied to estimate and correct the contribution of blink artifact, using linear regression. Trials containing horizontal or vertical eye movements other than blinks were rejected, as were those with $\mathrm{A} / \mathrm{D}$ saturation or baseline drift exceeding $\pm 50 \mu \mathrm{V}$.

ERPs (epoch length, 2,048 msec; 104-msec prestimulus baseline) were formed for each subject for different response categories corresponding to old items attracting correct source judgments in each condition (easy and hard hits) and correctly judged new items (correct rejections).

\section{RESULTS}

\section{Neuropsychological Test Performance}

The results of the neuropsychological test battery are summarized in Table 1. It can be seen that the groups were matched for level of education, although the older group had a higher verbal IQ, as measured by the NART,

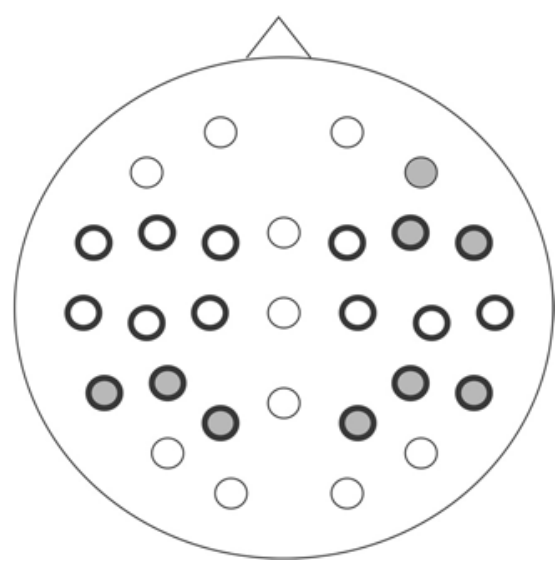

Figure 1. Schematic of the electrode montage. Bold circles signify sites employed in the principal analyses. Shading signifies sites employed for analyses of parietal (left for young, right for old) and right frontal old/new effects. and better picture-naming performance. As was expected, their long-term memory and fluid IQ were lower than those of the younger group.

\section{Behavioral Data}

Behavioral performance for each group is summarized in Table 2. Item memory-defined as the proportion of studied items judged old regardless of source accuracywas measured by the discrimination index $\operatorname{Pr}(p \mathrm{Hit}-$ $p$ False Alarm; Snodgrass \& Corwin, 1988). ${ }^{2}$ A 2 (group) $\times$ 2 (difficulty) analysis of variance (ANOVA) on these data gave rise to significant effects for both factors [group, $F(1,32)=21.11, p<.001 ;$ difficulty, $F(1,32)=108.89$, $p<.001]$ and for their interaction $[F(1,32)=41.71, p<$ $.001]$. Follow-up pairwise contrasts revealed significant group effects for both the easy $[F(1,32)=6.06, p<.02]$ and the hard $[F(1,32)=36.89, p<.001]$ conditions. The interaction reflected the fact that the reduction in item memory in older, as compared with younger, subjects was markedly greater in the hard condition. Source accuracy was quantified as the proportion of studied items judged old (i.e., accorded either a correct or an incorrect source judgment) that were assigned to the correct source. An ANOVA of these data also gave rise to main effects for group, difficulty, and their interaction $[F(1,32)=11.25, p<.005, F(1,32)=102.43, p<.001$, and $F(1,32)=21.94, p<.001$, respectively]. Pairwise contrasts revealed no group effect for the easy condition $(F<1)$ and a marked effect in the hard condition, in which source accuracy was poorer in the older group $[F(1,32)=$ $29.16, p<.001]$. In both groups, source accuracy was significantly lower for the hard condition [young, $t(17)=$ $14.45, p<.001$; old, $t(15)=9.16, p<.001]$.

Table 2 also shows reaction times (RTs) for each category of correct response. An ANOVA with group and response category (easy, hard, or correct rejection) as factors gave rise to a significant effect for condition $[F(1.3,40.4)=90.98, p<.001]$, but to no other effects. As can be seen from Table 2, intersubject variance differed markedly for responses to studied and unstudied items. When separate ANOVAs were performed for these two classes of items, a significant effect for category and a significant interaction of it with age were found for studied items $[F(1,32)=81.84, p<.001$, and $F(1,32)=$ $8.10, p<.01$, respectively]. This reflected a reversal of the groups' relative performance between the easy (older, $32 \mathrm{msec}$ faster) and the hard (older, $151 \mathrm{msec}$ slower) conditions. There were, however, no reliable group effects in either condition tested alone, although both groups responded more slowly in the hard than in the easy condition [young, $t(17)=5.40, p<.001$; old, $t(15)=7.07$, $p<.001]$. A significant effect of group was found for correct rejection RTs $[F(1,32)=8.65, p<.01]$, the older subjects responding more slowly.

\section{ERP Data}

Grand average ERP waveforms are shown for each group from selected electrode sites in Figures 2 and 3. The mean numbers of trials (range in brackets) making up 
Table 1

Subject Characteristics and Performance on Standardized

Neuropsychological Tests

\begin{tabular}{|c|c|c|c|c|c|}
\hline & \multicolumn{2}{|c|}{$\begin{array}{l}\text { Younger } \\
(n=18)\end{array}$} & \multicolumn{2}{|c|}{$\begin{array}{c}\text { Older } \\
(n=16)\end{array}$} & \multirow[b]{2}{*}{$p$} \\
\hline & $M$ & $S D$ & $M$ & $S D$ & \\
\hline Age & 21 & 4.3 & 70 & 3.9 & - \\
\hline Sex distribution & \multicolumn{2}{|c|}{14 Female } & \multicolumn{2}{|c|}{12 Female } & - \\
\hline Years of education & 15 & 2.1 & 16 & 3.1 & n.s. \\
\hline NART FSIQ estimate & 112 & 3.0 & 121 & 8.3 & $<.01$ \\
\hline Raven's Advanced Progressive Matrices II & 12 & 0.9 & 11 & 1.6 & $<.05$ \\
\hline Mini-Mental State & - & & 29 & 1.3 & - \\
\hline Warrington-McKenna Graded Naming & 22 & 3.1 & 26 & 3.5 & $<.01$ \\
\hline WAIS Digit Span & 10 & 1.8 & 9 & 2.1 & n.s. \\
\hline Verbal Paired Associates (WMS)-Immediate & 23 & 1.4 & 18 & 4.0 & $<.01$ \\
\hline Verbal Paired Associates (WMS)-Delayed & 8 & 0 & 7 & .08 & - \\
\hline Short Story Recall (AMIPB)-Immediate & 50 & 4.0 & 43 & 8.2 & $<.01$ \\
\hline Short Story Recall (AMIPB)-Delayed & 49 & 4.0 & 41 & 8.5 & $<.01$ \\
\hline FAS Verbal Fluency & 44 & 9.7 & 48 & 10.07 & n.s. \\
\hline
\end{tabular}

each subject's waveforms were 47 (22-65), 41 (19-56), and 54 (19-73) for easy source hit, hard source hit, and correct rejection item types, respectively, in the young group and 46 (28-65), 29 (17-50), and 55 (16-72), respectively, in the older group. Items that were wrongly classified during the study phase or that were not identified posttest (see the Method section) were excluded from the formation of ERPs regardless of response accuracy. On average, fewer than $1 \%$ of studied and new items were excluded for these reasons.

Turning first to the young subjects' data in Figure 2, their waveforms demonstrate several of the features reported in previous studies of source memory (see the introduction). Notably, relative to correct rejection ERPs, hit ERPs exhibit a parietally distributed positivity between approximately 300 and $800 \mathrm{msec}$, and a lateronsetting, right frontally distributed positivity.

As can be seen in Figure 3, the ERP effects in the older subjects appear to differ dramatically from those in the young group. ${ }^{3}$ There is little evidence of any old/new difference until approximately $400 \mathrm{msec}$ poststimulus, when a transient positive-going effect is evident at some sites, notably over the right hemisphere, accompanied at most other sites by a sustained negative-going effect that continues until the end of the recording epoch. There is also evidence at anterior right frontal sites of a lateonsetting, sustained positivity. Unlike the sustained negative and right frontal old/new effects, the transient positivity over the right posterior scalp is noticeably larger in the easy condition.

These data were analyzed in two stages. First, each group's data were analyzed separately, so as to determine in each case the pattern of old/new effects and their modulation by difficulty. Second, the old/new effects derived from the ERPs elicited by source hits in the easy condition - the condition in which source accuracy and RT were matched between the groups - were contrasted according to group. The between-groups analyses were conducted on difference scores (old - new), rather than on raw amplitude data, so as to allow a direct contrast of old/new effects. The foregoing analyses were conducted on the mean amplitudes (with respect to the mean of the prestimulus baseline) of four latency regions typical of those employed in studies of this type: $300-500 \mathrm{msec}, 500-800 \mathrm{msec}$, $800-1,100 \mathrm{msec}$, and 1,100-1,900 msec. ANOVAs were initially conducted on the set of 18 electrodes illustrated

Table 2

Behavioral Performance of Each Group on the Experimental Task

\begin{tabular}{|c|c|c|c|c|c|}
\hline & & \multicolumn{2}{|c|}{ Younger } & \multicolumn{2}{|c|}{ Older } \\
\hline & & $M$ & $S D$ & $M$ & $S D$ \\
\hline \multicolumn{6}{|l|}{ Accuracy } \\
\hline \multirow[t]{4}{*}{ Old items } & Easy item & .97 & .03 & .97 & .02 \\
\hline & Easy source & .88 & .07 & .87 & .07 \\
\hline & Hard item & .94 & .04 & .81 & .08 \\
\hline & Hard source & .81 & .05 & .69 & .08 \\
\hline \multirow[t]{2}{*}{ New items } & Correct rejection & .98 & .03 & .94 & .06 \\
\hline & False alarm & .01 & .02 & .06 & .05 \\
\hline \multirow[t]{2}{*}{$\mathrm{Pr}$} & Easy & .96 & .04 & .91 & .06 \\
\hline & Hard & .93 & .05 & .75 & .10 \\
\hline \multicolumn{6}{|c|}{ Reaction times (msec) } \\
\hline \multirow[t]{2}{*}{ Old items } & Easy-correct & 1,875 & 423 & 1,843 & 491 \\
\hline & Hard-correct & 2,073 & 419 & 2,224 & 477 \\
\hline New items & Correct rejection & 1,188 & 152 & 1,380 & 226 \\
\hline
\end{tabular}



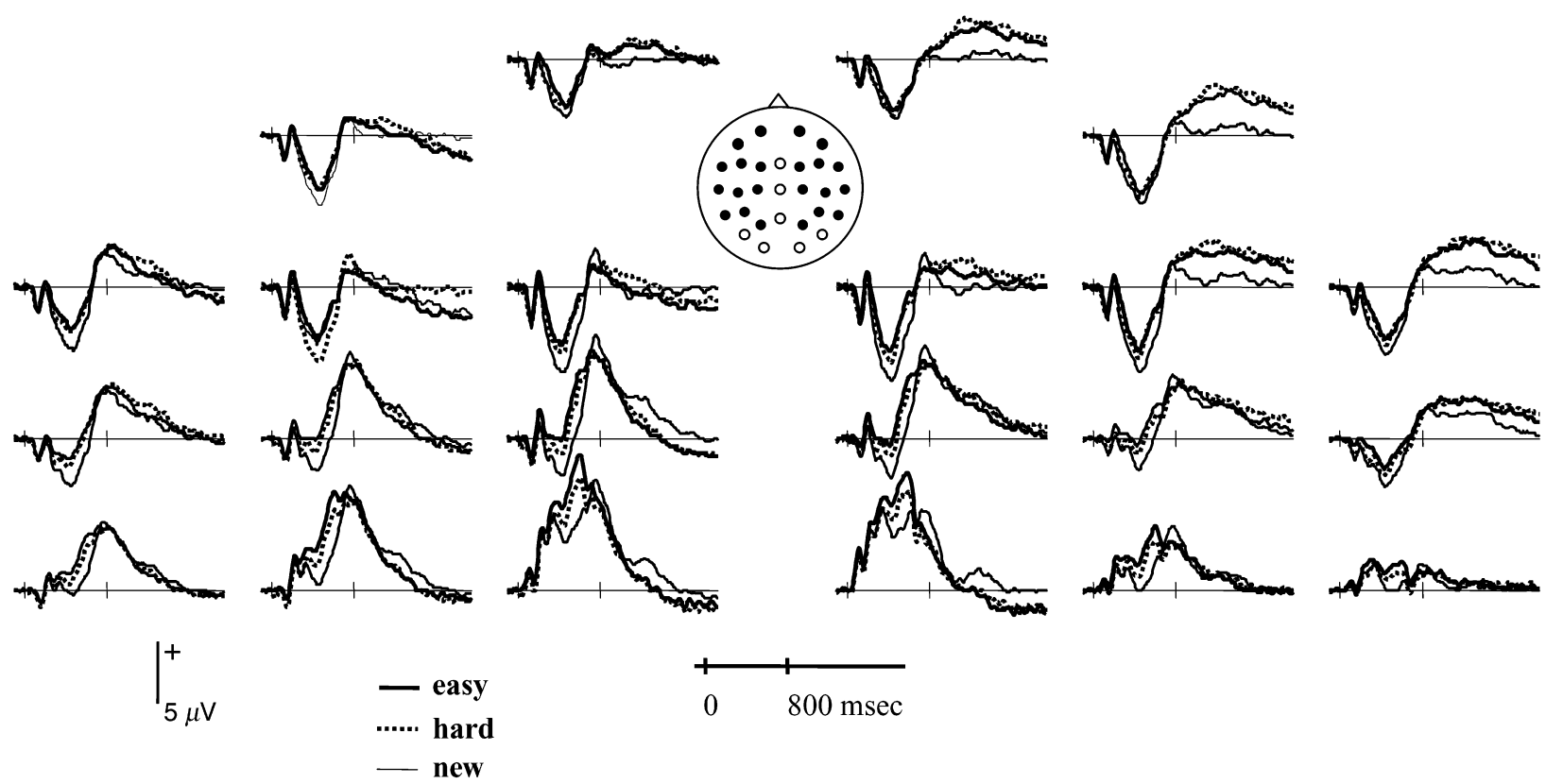

Figure 2. Young subjects: grand average waveforms elicited by correctly classified old items in each difficulty condition and by correctly classified new items. Electrode sites are indicated by the insert.

in Figure 1. These were factored according to hemisphere, anterior-posterior chain (frontal, anterior temporalcentral, or posterior temporal-parietal), and electrode site (inferior, middle, or superior). When the overall ANOVA gave rise to significant condition effects, subsidiary ANOVAs were conducted to separately contrast each hit condition with correct rejections and the two hit conditions. The results of these ANOVAs are summarized in Tables 3 and 4. Additional ANOVAs were conducted on data from a subset of the aforementioned sites or from sites additional to this set, as will be described below. In all cases, effects that did not involve the factors of ex-
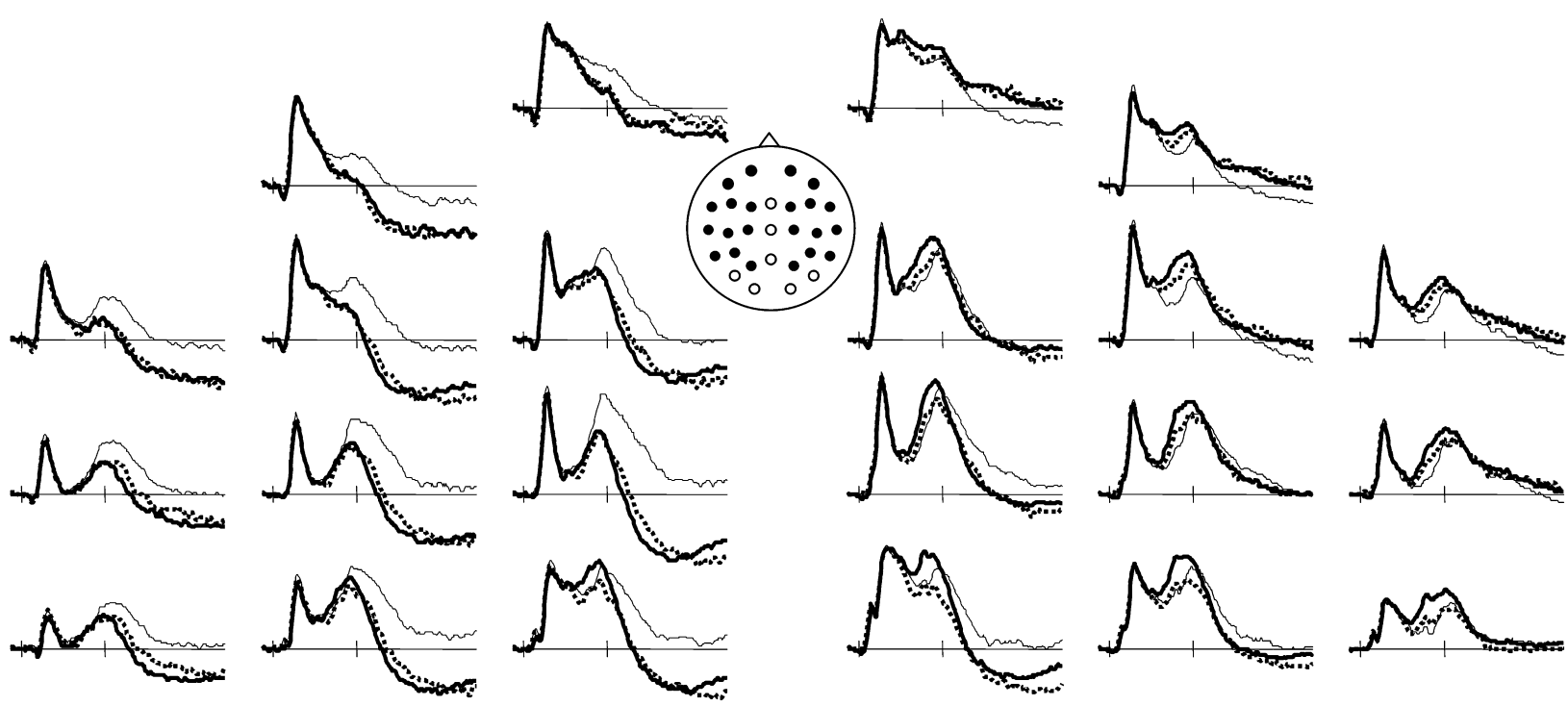

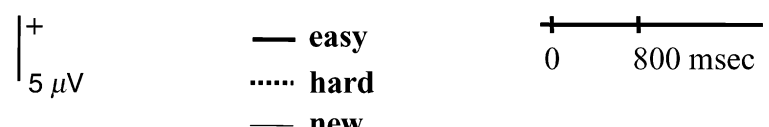

Figure 3. Older subjects: grand average waveforms elicited by correctly classified old items in each difficulty condition and by correctly classified new items. Electrode sites are indicated by the insert. 
perimental condition or subject group are not described. Contrasts of the topography of the two groups' old/new effects were conducted on difference scores derived from all 29 electrode sites after rescaling to remove differences in global amplitude between conditions (McCarthy \& Wood, 1985).

\section{Young Subjects}

As can be seen from Table 3, an ANOVA of the 300- to $500-\mathrm{msec}$ latency region revealed a variety of effects. In the case of the easy condition, the subsidiary ANOVA revealed the same pattern as in the overall analysis. For the hard condition, an effect of condition and its interaction with site were found, as well as an interaction between condition, hemisphere, and site. The ANOVA contrasting the two hit conditions revealed a main effect of condition, reflecting slightly more negative waveforms in the hard condition. Together, these findings reflect a predominantly central-parietal old/new effect, which was greater in magnitude in the easy than in the hard condition.

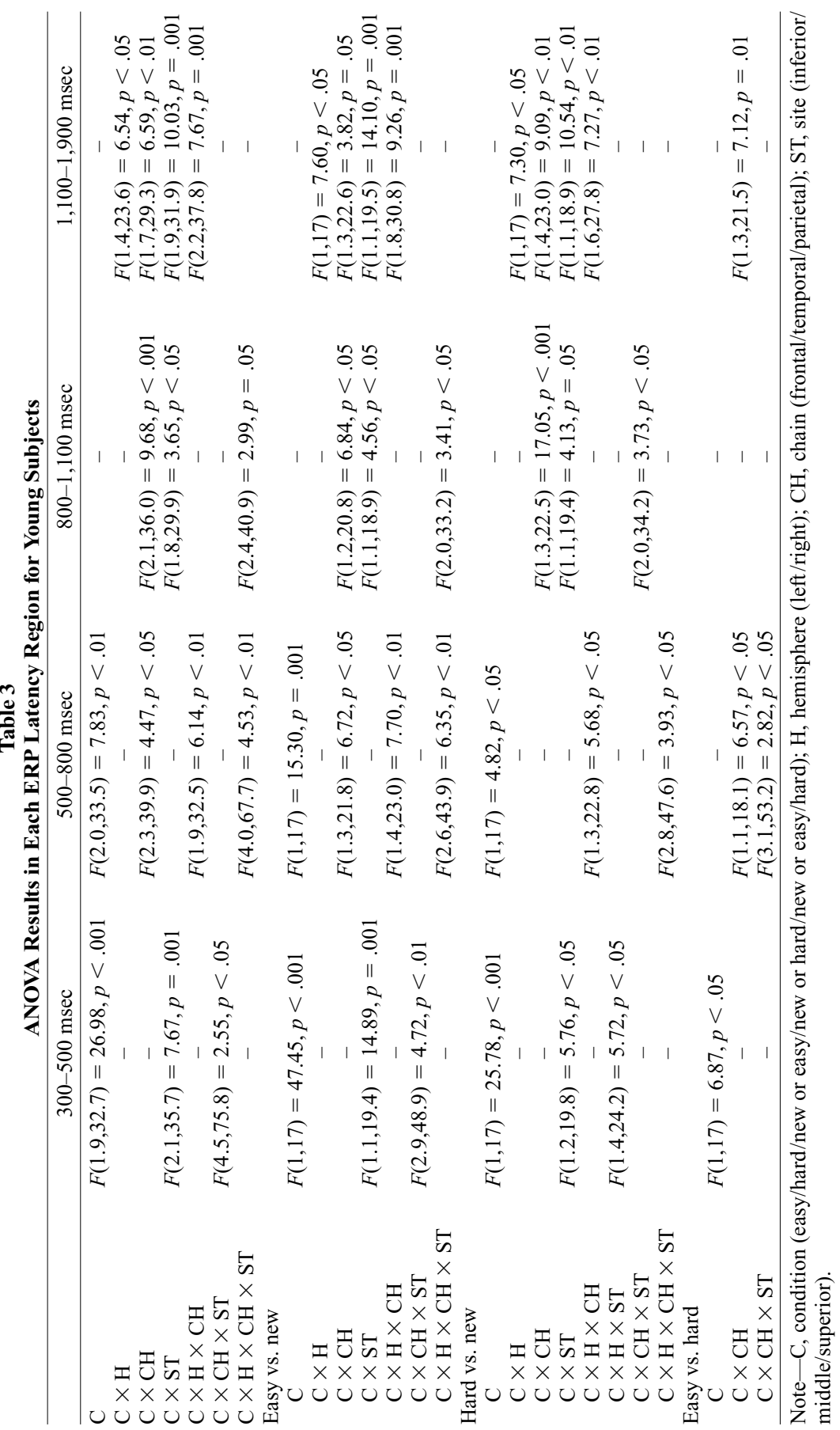


An ANOVA of the 500- to 800-msec data revealed a pattern of effects consistent with the development of the left-parietal old/new effect. ANOVAs of each class of hits separately revealed a common set of effects. In addition, for the easy condition only, there was an interaction between condition and chain. The outcome of the contrast between the two hit conditions reflected the tendency for ERPs elicited in the easy condition to be more positive going, especially at superior parietal electrodes, reflecting the greater magnitude of old/new effects at these sites in this condition.

An ANOVA of the 800- to 1,100-msec latency region gave rise to three significant effects. Subsidiary ANOVAs revealed the same two-way interactions for both easy and hard conditions. For the easy condition, there was also a significant condition $\times$ chain $\times$ site $\times$ hemisphere interaction, whereas for the hard condition, condition, chain, and site interacted. There were no effects involving condition in the ANOVA contrasting the two hit conditions. Together, these findings reflect the tendency for old/new effects in this latency region to be positive going over the frontal scalp but to reverse polarity over posterior regions.

The pattern of effects from the ANOVA of the 1,100to $1,900-\mathrm{msec}$ latency region was consistent with the emergence of a right frontal old/new effect. The same pattern was evident in each of the subsidiary ANOVAs, with interactions between condition and hemisphere, condition and chain, condition and site, and condition, hemisphere, and chain. An ANOVA of the two hit conditions gave rise to an interaction between condition and chain, reflecting the tendency for the waveforms from the hard condition to be slightly more positive at frontal sites.

Left parietal and right frontal effects. Additional contrasts were performed to assess in more detail the left parietal and right frontal old/new effects according to difficulty. Analyses of the left parietal effects were conducted on the 500- to 800 -msec latency region, using data from the electrode sites indicated in Figure 1. Separate ANOVAs of the easy and the hard conditions (each vs. correct rejections) revealed, in each case, significant effects of condition [easy, $F(1,17)=46.27, p<.001$; hard, $F(1,17)=7.36, p<.05]$, along with a condition $\times$ site interaction for the easy condition only $[F(1.5,26.1)=$ $4.28, p<.05]$. The contrast between the two hit conditions gave rise to both a condition effect $[F(1,17)=7.18$, $p<.05]$ and a condition $\times$ site interaction $[F(1.7,28.9)=$ $6.90, p<.01]$. These findings indicate that whereas both easy and hard source hits elicited reliable old/new effects, the effects were significantly smaller in the hard condition, especially at more superior sites.

Right frontal effects were evaluated in the 1,100- to 1,900 -msec latency region from the sites indicated in Figure 1. Separate ANOVAs of the easy and hard conditions gave rise in each case to significant effects of condition [easy, $F(1,17)=17.08, p=.001$; hard, $F(1,17)=$ $21.50, p<.001]$. An ANOVA of the two hit conditions gave rise to no significant effects. These findings indicate that right frontal effects of equivalent magnitude were elicited in the easy and the hard conditions.

\section{Older Subjects}

The results of the ANOVAs for each latency interval are shown in Table 4. An ANOVA of the 300- to 500-msec latency region gave rise to no significant effects and is omitted from the table.

The analysis of the 500- to $800-\mathrm{msec}$ latency region revealed reliable effects for condition and its interaction with all of the topographic variables, either singly or in combination. Separate ANOVAs for each hit condition yielded an almost identical pattern of effects in both cases. The effects reflected the tendency for old/new effects in this latency range to be more negative going over the left hemisphere, especially at more lateral and anterior sites. The contrast between the two hit conditions also revealed a variety of effects. These reflected more negative-going waveforms for the hard condition, most markedly at posterior right-hemisphere sites.

An analysis of the 800- to 1,100 -msec latency region gave rise to a pattern of effects similar to that seen in the previous region. The subsidiary ANOVAs revealed identical effects for the different difficulty conditions, again reflecting the tendency for old/new effects to be negative going over left-hemisphere sites and positive going over the right hemisphere. The outcome of the contrast between the two source hit conditions reflected the tendency for the waveforms from the easy condition to be slightly more negative going than those from the hard condition at left-hemisphere sites but to be more positive going at right posterior electrodes.

Table 4 shows that the pattern of effects above continues for the 1,100- to 1,900-msec latency region. Again, the separate ANOVAs for each hit condition gave rise to largely equivalent findings, although for the hard condition only, there was an additional interaction between condition, hemisphere, and site. The ANOVA between the two hit conditions revealed one effect only, for the interaction between condition, hemisphere, and chain. This reflected the tendency for ERPs to be more negative going at posterior electrodes in the hard condition than in the easy condition, especially at right posterior sites.

Parietal and right frontal effects. Additional analyses focused on site-specific effects. An inspection of Figure 3 shows little or no sign of a left parietal old/new effect, seemingly as a result of its overlap with the large, left-lateralized negative wave elicited by the hits. The influence of this effect appears much less apparent over the right hemisphere, and accordingly, the reliability of the parietal old/new effect and its sensitivity to difficulty were tested using the 500- to $800-\mathrm{msec}$ data from the three sites homotopic with those employed for the equivalent analysis of the young subjects. The right frontal old/new effect was contrasted using the same sites as those employed for the young subjects.

An ANOVA of the right parietal data for the easy condition gave rise to a significant condition effect $[F(1,15)=$ $14.20, p<.01]$, reflecting the positive-going old/new effects evident at these sites (see Figure 3 ). For the hard condition, there was a condition $\times$ site interaction $[F(1.2,17.4)=9.45, p<.01]$, reflecting a transition 
Table 4

ANOVA Results in Each ERP Latency Region for Older Subjects

\begin{tabular}{|c|c|c|c|}
\hline & $500-800 \mathrm{msec}$ & $800-1,100 \mathrm{msec}$ & $1,100-1,900 \mathrm{msec}$ \\
\hline$\overline{\mathrm{C}}$ & $F(1.6,24.7)=3.49, p=.05$ & $F(1.7,25.4)=11.12, p=.001$ & $F(1.8,26.8)=21.60, p<.001$ \\
\hline $\mathrm{C} \times \mathrm{H}$ & $F(1.3,19.1)=15.95, p<.001$ & $F(1.2,18.2)=20.18, p<.001$ & $F(1.2,18.6)=19.26, p<.001$ \\
\hline $\mathrm{C} \times \mathrm{CH}$ & - & - & $F(1.5,23.1)=5.50, p<.05$ \\
\hline $\mathrm{C} \times \mathrm{ST}$ & - & $F(1.8,26.3)=11.15, p<.001$ & $F(2.2,32.4)=22.84, p<.001$ \\
\hline $\mathrm{C} \times \mathrm{H} \times \mathrm{CH}$ & $F(2.9,44.2)=11.17, p<.001$ & $F(2.6,38.8)=7.96, p=.001$ & $F(2.1,32.0)=8.01, p=.001$ \\
\hline $\mathrm{C} \times \mathrm{H} \times \mathrm{ST}$ & 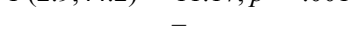 & - & $F(1.7,25.4)=3.87, p<.05$ \\
\hline $\mathrm{C} \times \mathrm{CH} \times \mathrm{ST}$ & - & $F(3.3,49.3)=4.82, p<.01$ & $F(3.5,53.0)=7.63, p<.001$ \\
\hline $\mathrm{C} \times \mathrm{H} \times \mathrm{CH} \times \mathrm{ST}$ & $F(3.4,51.7)=6.75, p<.001$ & $F(2.3,34.5)=5.19, p<.01$ & $F(2.3,34.4)=3.47, p<.05$ \\
\hline \multicolumn{4}{|l|}{ Easy vs. new } \\
\hline $\mathrm{C}$ & - & $F(1,15)=12.84, p<.01$ & $F(1,15)=25.09, p<.001$ \\
\hline $\mathrm{C} \times \mathrm{H}$ & $F(1,15)=19.49, p=.001$ & $F(1,15)=26.17, p<.001$ & $F(1,15)=23.88, p<.001$ \\
\hline $\mathrm{C} \times \mathrm{CH}$ & - & - & $F(1.2,17.8)=5.03, p<.05$ \\
\hline $\mathrm{C} \times \mathrm{ST}$ & - & $F(1.2,17.9)=18.83, p<.001$ & $F(1.1,17.1)=23.15, p<.001$ \\
\hline $\mathrm{C} \times \mathrm{H} \times \mathrm{CH}$ & $F(2.0,29.7)=13.83, p<.001$ & $F(1.9,28.6)=6.64, p<.01$ & $F(1.5,23.1)=4.12, p<.05$ \\
\hline $\mathrm{C} \times \mathrm{CH} \times \mathrm{ST}$ & - & $F(2.5,37.8)=5.87, p<.01$ & $F(2.3,34.3)=9.27, p<.001$ \\
\hline $\mathrm{C} \times \mathrm{H} \times \mathrm{CH} \times \mathrm{ST}$ & $F(2.3,34.8)=10.76, p<.001$ & $F(1.6,24.5)=6.23, p<.01$ & $F(1.5,22.2)=3.66, p=.05$ \\
\hline \multicolumn{4}{|l|}{ Hard vs. new } \\
\hline $\mathrm{C}$ & - & $F(1,15)=17.83, p=.001$ & $F(1,15)=46.15, p<.001$ \\
\hline $\mathrm{C} \times \mathrm{H}$ & $F(1,15)=11.19, p<.01$ & $F(1.1,15)=13.95, p<.01$ & $F(1,15)=17.47, p=.001$ \\
\hline $\mathrm{C} \times \mathrm{CH}$ & - & - & $F(1.2,18.2)=7.41, p=.01$ \\
\hline $\mathrm{C} \times \mathrm{ST}$ & - & $F(1.1,16.6)=10.91, p<.01$ & $F(1.2,18.0)=36.78, p<.001$ \\
\hline $\mathrm{C} \times \mathrm{H} \times \mathrm{CH}$ & $F(1.7,25.4)=14.73, p<.001$ & $F(2.0,29.3)=12.82, p<.001$ & $F(1.7,25.1)=12.01, p<.001$ \\
\hline $\mathrm{C} \times \mathrm{H} \times \mathrm{ST}$ & - & - & $F(1.3,19.6)=4.74, p<.05$ \\
\hline $\mathrm{C} \times \mathrm{CH} \times \mathrm{ST}$ & - & $F(2.0,30.5)=3.32, p<.05$ & $F(2.3,35.1)=4.01, p<.001$ \\
\hline $\mathrm{C} \times \mathrm{H} \times \mathrm{CH} \times \mathrm{ST}$ & $F(2.4,35.3)=5.14, p<.01$ & $F(2.1,31.6)=4.92, p<.05$ & $F(1.9,27.9)=4.01, p<.05$ \\
\hline \multicolumn{4}{|l|}{ Easy vs. hard } \\
\hline $\mathrm{C}$ & $F(1,15)=10.44, p<.01$ & - & - \\
\hline $\mathrm{C} \times \mathrm{H}$ & $F(1,15)=14.35, p<.01$ & $F(1,15)=17.77, p=.001$ & - \\
\hline $\mathrm{C} \times \mathrm{CH}$ & $F(1.3,19.6)=5.63, p<.05$ & - & - \\
\hline $\mathrm{C} \times \mathrm{ST}$ & $F(1.3,18.9)=8.82, p<.01$ & - & - \\
\hline $\mathrm{C} \times \mathrm{H} \times \mathrm{CH}$ & - & - & $F(1.6,23.3)=8.67, p<.01$ \\
\hline $\mathrm{C} \times \mathrm{CH} \times \mathrm{ST}$ & $F(2.3,34.1)=3.32, p<.05$ & $F(2.8,41.7)=5.90, p<.01$ & - \\
\hline
\end{tabular}

Note-C, condition (easy/hard/new or easy/new or hard/new or easy/hard); H, hemisphere (left/right); CH, chain (frontal/temporal/ parietal); ST, site (inferior/middle/superior).

from positive-going effects at lateral sites to negativegoing effects adjacent to the midline. The contrast for the two hit conditions gave rise to a significant effect for condition and a significant interaction with site $[F(1,15)=$ $34.34, p<.001$, and $F(1.7,24.8)=10.49, p=.001$, respectively]. These effects reflected the greater positivity of the easy hit ERPs and the fact that this difference was largest at the site nearest the midline.

An ANOVA of the right frontal data for the easy and hard conditions revealed, in each case, significant effects of condition [easy, $F(1,15)=5.16, p<.05$; hard, $F(1,15)=9.14$, $p<.01]$. The contrast of the two hit conditions revealed no significant effects. Together, these analyses indicate the presence of reliable right frontal effects in the older group that, in contrast to the parietal effects described previously, were unaffected by the difficulty manipulation.

\section{Between-Groups Comparisons}

Frontal and parietal waveforms for the easy and the new conditions are illustrated for each group in Figure 4, where it can be seen that old/new effects demonstrate more marked differences over the left hemisphere than over the right hemisphere at both sets of sites. These effects are shown quantitatively in Figure 5. The results of the ANOVAs contrasting the two groups' old/new effects are summarized in Table 5. In keeping with the impression given from Figures 4 and 5, there were significant effects involving the group factor in every latency region. In the 300- to 500-msec region, the effects reflected the greater overall magnitude of the (positive-going) old/new effects in the younger subjects. In the three later latency regions, however, the results reflected the very different patterns of the old/new effects in the two groups. Strikingly, in each of these latency regions, hemisphere-specific ANOVAs demonstrated that group effects were reliable for left hemisphere sites [500-800 msec, $F(1,32)=8.38$, $p<.01 ; 800-1,100 \mathrm{msec}, F(1,32)=18.15, p<.001$; $1,100-1,900 \mathrm{msec}, F(1,32)=15.42, p<.001]$ but were uniformly nonsignificant over the right hemisphere $[F(1,32) \leq 2.22]$. Two site-specific ANOVAs - one contrasting right parietal old/new effects in the 500- to 800 -msec latency region, and the other right frontal effects between 1,100 and 1,900 msec-were consistent with this finding: In neither case was there any evidence of a reliable effect involving group.

Scalp topography of old/new effects. A further ANOVA was conducted to contrast the scalp topography of the two groups' old/new effects in the three latency ranges - 500-800, 800-1,100, and 1,100-1,900 msecin which they were independently reliable. The ANOVA 
YOUNG

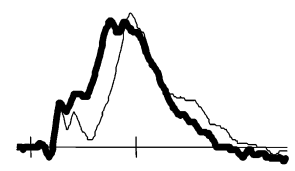

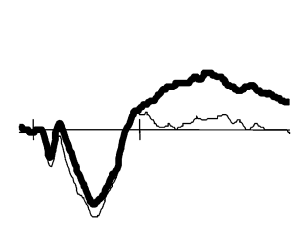
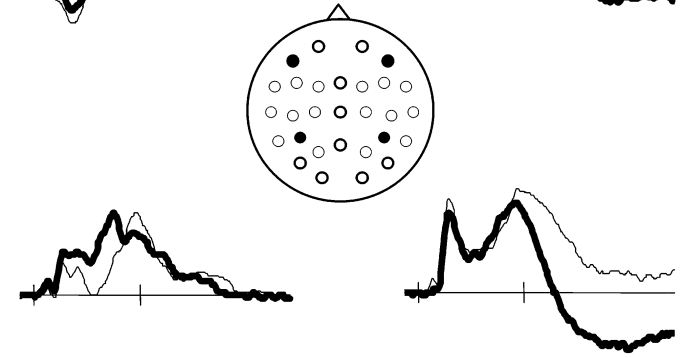

$\left.\right|_{5 \mu \mathrm{V}} ^{+}$

\section{OLDER}
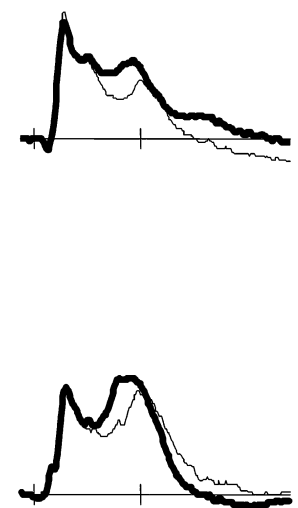

easy

new

Figure 4. Grand average waveforms from lateral frontal and parietal electrodes elicited by correctly classified items in the easy and the new conditions.

employed the factors of group, electrode site, and latency region and revealed a significant effect of site $[F(6.0,190.8)=7.87, p<.001]$, along with interactions between the factors of group and site $[F(6.0,190.8)=$ $3.76, p=.001]$, and group, latency region, and site $[F(6.0,191.3)=6.05, p<.001]$. Separate ANOVAs for each latency region gave rise to group $\times$ site interactions for the 500- to 800 -msec and 800 - to $1,100-\mathrm{msec}$ regions $[F(5.6,180.3)=4.88, p<.001$, and $F(5.5,177.1)=3.88$, $p<.005$, respectively], but not for the $1,100-$ to $1,900-\mathrm{msec}$ region. These effects confirm the impression given by Figure 6 that the scalp distributions of the old/new effects in the two groups differed more markedly in the earlier two regions than in the 1,100 - to 1,900 -msec region.

\section{Summary of ERP Findings}

ERPs from the young subjects conformed to the pattern reported in several previous studies of source memory, demonstrating large, robust left parietal and right frontal old/new effects. Relative to the easy condition,

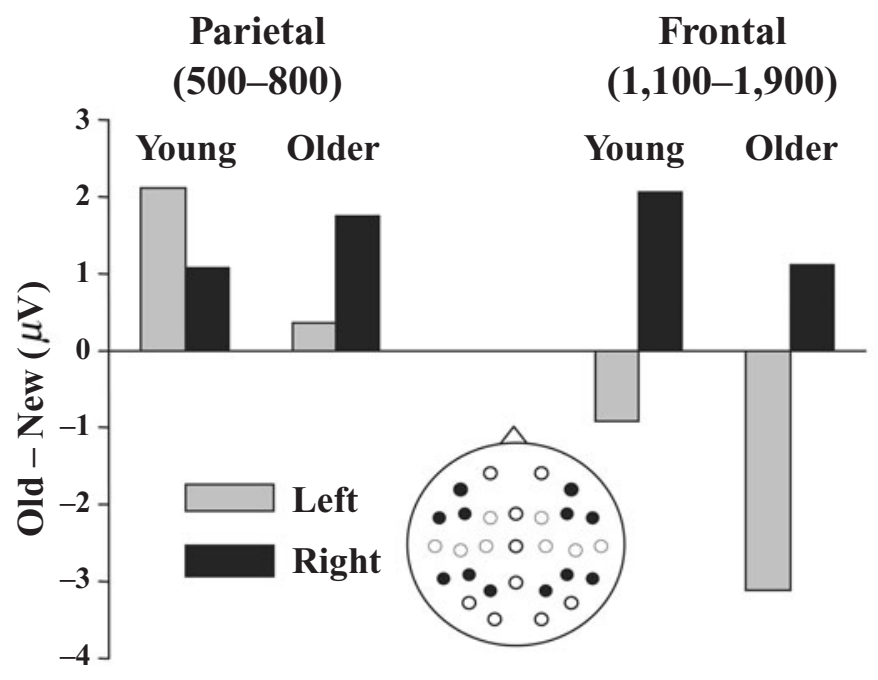

Figure 5. Mean amplitude of old/new effects (correct old - correct new) in the easy condition, for left and right parietal $(500-800 \mathrm{msec})$ and frontal (1,100-1,900 msec) scalp sites according to group. Data were collapsed over the sites indicated in the insert. 
Table 5

ANOVA Results in Each ERP Latency Region for Between-Groups Comparisons

\begin{tabular}{llclc}
\hline & \multicolumn{1}{c}{$300-500 \mathrm{msec}$} & $500-800 \mathrm{msec}$ & $800-1,100 \mathrm{msec}$ & $1,100-1,900 \mathrm{msec}$ \\
\hline $\mathrm{GP}$ & $F(1,32)=16.96, p<.001$ & - & $F(1,32)=9.09, p<.01$ & $F(1,32)=9.86, p<.01$ \\
$\mathrm{GP} \times \mathrm{H}$ & $F(1,32)=5.59, p<.05$ & $F(1,32)=19.90, p<.001$ & $F(1,32)=12.61, p<.001$ & $F(1,32)=7.75, p<.01$ \\
$\mathrm{GP} \times \mathrm{CH}$ & - & - & $F(1.2,39.3)=4.54, p<.05$ & - \\
$\mathrm{GP} \times \mathrm{ST}$ & $F(1.2,37.6)=6.16, p<.05$ & - & - & - \\
$\mathrm{GP} \times \mathrm{CH} \times \mathrm{ST}$ & $F(2.9,92.7)=2.98, p<.05$ & - & $F(2.8,90.5)=3.10, p<.05$ & - \\
\hline
\end{tabular}

Note-GP, group (young/old); H, hemisphere (left/right); CH, chain (frontal/temporal/parietal); ST, site (inferior/middle/superior).

the parietal effect in the hard condition was attenuated. By contrast, the right frontal effect was unaffected by the difficulty manipulation.

The pattern of ERP effects in the older subjects differed markedly from that in the young group. Parietal and frontal old/new effects were evident over the right hemisphere only. Echoing the findings from the young subjects, the parietal effects were attenuated in the difficult condition, whereas the frontal effects were unaffected by the difficulty manipulation. Over the left hemisphere, ERPs elicited by both classes of old item were dominated by a sustained negativity. Consistent with the findings obtained from each group separately, betweengroups contrasts revealed that old/new effects were statistically equivalent over the right hemisphere but differed significantly at left-hemisphere sites. These findings are well illustrated in Figures 4 and 5.

\section{DISCUSSION}

\section{Behavioral Performance}

The findings for the hard condition demonstrated the typical pattern of age-related differences for tasks of this kind (Spencer \& Raz, 1995), in that memory for both items and their sources were substantially lower in the older group. The attempt to match performance in the easy condition was, however, reasonably successful. Whereas item memory remained slightly lower in the older subjects (by a substantially smaller fraction than in the hard condition), accuracy of source judgments did not differ between the groups. In this condition, therefore, the ERP correlates of successful recollection can be contrasted between the groups in the absence of the possible confounding effects of differential guessing (see the introduction). This is not to say, however, that the cognitive processes associated with correct source judgments were precisely equivalent in the two groups. First, the method employed to equate performance (different numbers of study exposures) may have engendered differential retrieval processing in the two groups and, thus, contributed to age-related ERP effects. Second, although source accuracy was equated across the groups in the easy condition, item memory was slightly but significantly lower in the older subjects, suggesting that the relative contributions of familiarity and recollection were not perfectly matched. On the assumption
$500-800$

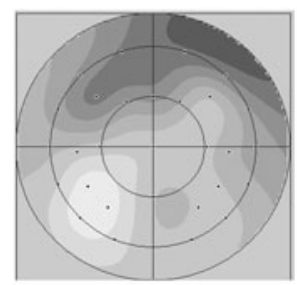

$-1.0-2.5$

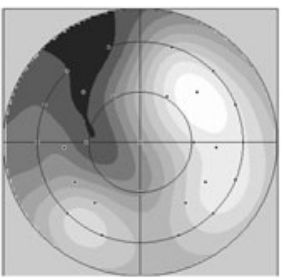

$-1.7-2.5$
800-1,100

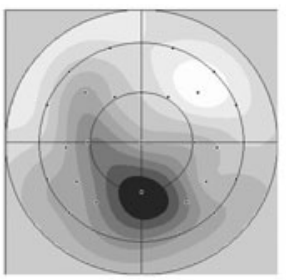

$-2.0-2.0$

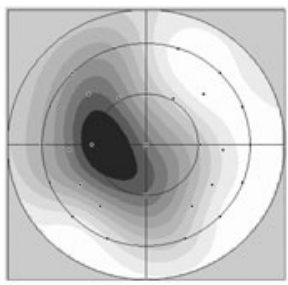

$-5.5-0.5$
$1,100-1,900$

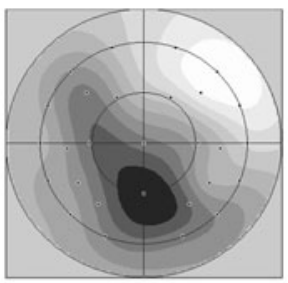

$-2.5-2.5$

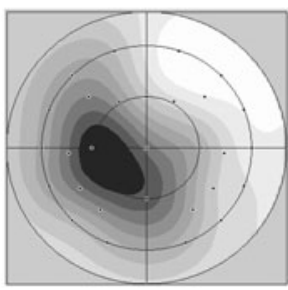

$-6.0-1.3$

Figure 6. Spherical spline maps illustrating the scalp topographies of young and older subjects' old/new effects in the 500- to 800-, 800- to 1,100-, and 1,100- to 1,900-msec latency regions. Lighter shading indicates greater positivity. Maps are scaled to maximum and minimum voltages, the values of which are indicated beneath. 
that familiarity and recollection are independent (Yonelinas, 2001), this raises the possibility that source hits were less likely to be both recollected and familiar in the older than in the younger subjects. Thus, some of the findings for the between-groups ERP contrasts might not reflect age effects per se but, rather, the differential influences of recollection and familiarity in the two groups (see Rugg \& Morcom, in press).

Resolution of these issues will have to wait for findings from similar studies in which performance levels are equated by other means (e.g., differential study-test delay; cf. Morcom \& Rugg, 2004). That said, the most marked between-groups difference observed in the presented data - the sustained left-hemisphere negativity in the ERPs of the older subjects - cannot be a simple consequence of the manipulation employed to match performance, because the effect was evident in both easy and hard conditions. One caveat remains, however. Whereas RT for easy source hits did not differ between the groups, older subjects, on average, took some $200 \mathrm{msec}$ longer to reject new items. It is possible that between-groups differences in ERP old/new effects were, to some extent, a consequence of this disparity in RT.

\section{ERP Data}

The young subjects' ERP old/new effects were similar to those described in several previous studies of source memory (e.g., Mark \& Rugg, 1998; Senkfor \& Van Petten, 1998; Trott et al., 1997; Wegesin et al., 2002; Wilding, 1999; Wilding \& Rugg, 1996). The effects evolved from a roughly symmetrical modulation in the 300 - to $500-\mathrm{msec}$ latency range to a left posterior maximum and culminated in a sustained right frontal positivity that coexisted with a negative-going effect over the posterior midline. The effects of difficulty were most marked in the latency range of the left parietal effect, which was significantly smaller in the hard condition. There was no influence of difficulty, however, on the right frontal effect. These findings can be understood in terms of the differential influence of guessing on the two classes of effects. As was discussed in the introduction, as source memory declines, the proportion of correct source judgments due to lucky guesses increases. In the present case, according to the model suggested by Rugg, Schloerscheidt, and Mark (1998), ${ }^{4}$ these proportions would have risen from .24 of the judgments in the easy condition to .38 in the hard condition. On the assumption that the left parietal effect is elicited only when recollection is successful (e.g., Curran, 2000), the proportion of trials containing the effect and, hence, the amplitude of the effect when averaged across trials would have been smaller in the hard condition. By contrast, if the right frontal effect reflects the evaluation of the products of a retrieval attempt (Rugg et al., 2002; see Van Petten, Luka, Rubin, \& Ryan, 2002, for a related proposal), there is no necessary reason why the effect would be modulated by difficulty. In the present study, it would appear that whether recollection was successful or incomplete, the subjects engaged postretrieval monitoring and evaluation to an equivalent extent (so far as is detectable through scalp potentials) in an effort to select the appropriate response (cf. Rugg, Allan, \& Birch, 2000).

Turning to the ERP data from the older subjects, several features stand out. First, consistent with previous reports (Mark \& Rugg, 1998; Wegesin et al., 2002), the onset of old/new effects was delayed relative to that of the young group. Second, over much of the left hemisphere, ERPs to old items were dominated by a sustained, central-maximum negativity that appears to swamp positive-going effects. Third, positive-going effects were evident over the right hemisphere. Here, as in the young group, a relatively early parietal effect was found to be sensitive to the difficulty manipulation, whereas a later frontal effect was not.

In several respects, the present findings from the older group are qualitatively similar to those reported by Trott et al. (1997; Trott et al., 1999) and Wegesin et al. (2002). In particular, their most striking feature, the large, sustained negativity elicited by old items, was foreshadowed by these previous studies, in both of which a similar, albeit somewhat smaller and more symmetric, effect was evident. As was noted by Wegesin et al., the central distribution of this effect suggests that it is distinct from the more posterior negativity that has sometimes been reported in studies of source memory in young subjects (e.g., Wilding \& Rugg, 1997; for a review, see Johansson \& Mecklinger, 2003) and that was evident in the young subjects' data in the present study. A clue to the functional significance of the present central effect comes from the findings of Cycowitz, Friedman, and Snodgrass (2001) and Cycowitz and Friedman (2003). In both studies, the authors reported that a similar, although more symmetrical, effect was elicited in young subjects in tasks requiring a source judgment based on the sensory attributes of pictorial test items. Because the size of the effect did not vary with source accuracy, Cycowitz et al. proposed that it reflected the engagement of search processes directed at the recovery of visual information from stored study episodes, rather than processes that follow the successful recovery of source information (see also Wegesin et al., 2002). Further support for this proposal comes from Johansson, Stenberg, Lindgren, and Rosen (2002; see Johansson \& Mecklinger, 2003, for further analysis of the same data set), who employed a reality-monitoring task in which subjects judged whether old words had been associated at study with a real or imagined picture-a task that would likely involve attempts to recover visual detail. Old item ERPs demonstrated a prominent, centroparietal negativity, with a slight asymmetry in favor of the left hemisphere.

The present findings are consistent with the proposal of Cycowitz et al. (2001). Specifically, the central negativity evident in the older subjects' waveforms was influenced to only a small extent by the difficulty manipulation, despite the fact that accuracy and RT differed markedly between the two conditions. Thus, consonant with the findings of Cycowitz et al. and Johansson and Mecklinger (2003), the effect was insensitive to the prob- 
ability of successful recollection and did not covary in any simple way with response latency. From the perspective of the functional interpretation of the effect proposed by Cycowitz et al., the present findings suggest that the young and the older subjects differed in the degree to which they attempted to retrieve visual information to perform the source judgment task (see Wegesin et al., 2002, for a similar suggestion). One possibility is that younger subjects relied mainly upon retrieval of abstract or conceptual information associated with each item (e.g., a record of the decision it attracted at study), whereas older subjects retrieved information of a more literal kind (e.g., recapitulation of the appearance of the item and, perhaps, its associated task cue). By this account, therefore, the similar performance of the two groups disguises the fact that their source judgments were based on recovery of qualitatively distinct forms of information. An important task for the future is to identify the factors that predispose older subjects to preferentially retrieve visually based, rather than more abstract, information. One possibility is that this predisposition reflects agerelated differences in the capacity to encode the different kinds of information. By this argument, older individuals are disproportionately impaired in the encoding of abstract, as opposed to sensory, features of an episode, so that the latter are more accessible at the time of retrieval. A second possibility, which is not mutually exclusive, is that older subjects are more prone to adopt a retrieval orientation (Rugg \& Wilding, 2000) that biases the processing of retrieval cues in favor of the recovery of sensory, rather than abstract, information.

As was noted in the introduction, older subjects' ERPs in the study of Mark and Rugg (1998) showed no sign of the central negativity that is so prominent here. Intriguingly, alone among the ERP studies of aging and source memory cited above, Mark and Rugg employed auditory, rather than visual, study items. If, as has been proposed (Cycowicz et al., 2001), the central negativity is specifically associated with the recovery of visual episodic detail, this might account for the failure to find an age-related negative old/new effect in Mark and Rugg's study. To reconcile this suggestion with the findings of Trott et al. (1999) and Wegesin et al. (2002), both of whom employed verbal materials, it is, however, necessary to assume that source judgments in older subjects are more reliant on visual information than are those in the young when the test items are words, as well as when they are pictures.

The size of the negative old/new effect in the older subjects' ERPs makes it impossible to evaluate the left parietal old/new effect at the left posterior electrode sites conventionally employed for this purpose. The seemingly analogous effect at homologous sites over the right hemisphere was amenable to analysis, however. On the assumption that the effects at these sites are representative of the recollection-related neural activity reflected by the left parietal effect, two conclusions are possible. First, when probability of successful recollection is equated, there is little evidence of an age-related reduction in the magnitude of the left parietal effect. Thus, those aspects of recollection held to be associated with the effect-for example, representation of retrieved episodic information (Rugg \& Allan, 2000) - appear to be unaffected by age. Similar findings were reported by Trott et al. (1999), Mark and Rugg (1998), and Wegesin et al. (2002; although in this case, only in the analysis of the effect as defined by current source density, rather than by voltage).

A second aspect of the older subjects' parietal old/new effects concerns the sensitivity of the effects to difficulty. As was the case for the young subjects, the effects were smaller in the hard condition. The influence of difficulty can be explained in the same terms as the difficulty effects in the young subjects - namely, as a consequence of the diluting effect of guessing. The seemingly more marked difficulty effect in the older subjects presumably reflects the greater disparity in the performance of these subjects between the easy and the hard conditions. The proportion of older subjects' source hits that were guessed to be old in the easy condition was comparable to that in the young group (about .25). This rose, however, to .62 in the hard condition, as opposed to .38 in this condition for the young subjects (the foregoing estimates are based on the equation given in note 4). Notwithstanding the difficulties surrounding attempts to match task performance that were discussed earlier, the findings for the parietal old/new effects underscore the importance of matching performance when retrievalrelated neural activity is compared across different subject groups (see also Rugg \& Morcom, in press). Had the contrast between these old/new effects been performed for the hard condition - the condition in which typical age-related performance differences were evident-it might erroneously have been concluded that the effects diminish with age.

The final aspect of the results to be discussed is the right frontal old/new effect. The effect in the older subjects was statistically reliable and, although numerically smaller, did not differ significantly in magnitude from the effect in the young. Moreover, as in the young subjects, and presumably for the same reason, the right frontal effect in the older group was insensitive to the difficulty manipulation. These findings are consistent with those of Mark and Rugg (1998), who also reported that the right frontal effect did not vary with age. The findings are also consistent with much of the evidence from functional neuroimaging studies in which the effects of aging on retrieval-related prefrontal activity were investigated (for reviews, see Cabeza, 2002; Grady \& Craik, 2000). The blocked designs employed in most of these studies make them difficult to compare directly with the event-related designs employed in ERP investigations. Nonetheless, the results of these studies do not suggest that retrievalrelated prefrontal activity diminishes with age; if anything, there is a tendency for such activity to be distributed more bilaterally than in young subjects (e.g., Madden et al., 1999; see Cabeza, 2002, for a review). In the one published 
neuroimaging study we are aware of in which an eventrelated design allowed the direct investigation of old/new effects (Daselaar, Veltman, Rombouts, Raaijmakers, \& Jonker, 2003), there were no differences in prefrontal effects between healthy young and older subjects. And in a recent fMRI experiment from our own laboratory (Morcom \& Rugg, unpublished observations), which employed the same experimental procedure as that in the present study, recollection-related activity in the lateral prefrontal cortex (operationalized, as in the present case, as source hits - correct rejections) was of greater magnitude in the older group. These neuroimaging findings converge with the findings from Mark and Rugg (1998) and the present study to suggest that recruitment of the prefrontal cortex during successful episodic retrieval is not necessarily compromised by age. Of course, this does not mean that the cognitive operations supported by this region are equally efficient regardless of age; it is entirely possible that they proceed more slowly or less accurately in older individuals. By itself, therefore, the findings discussed above do not rule out the possibility that prefrontally mediated retrieval processes, such as postretrieval monitoring, become less efficient with increasing age. The findings do suggest, however, that any agerelated decrement in these processes is not due to underrecruitment of brain regions that support the same processes in young individuals.

The present findings for the right frontal effect, along with those of Mark and Rugg (1998), differ markedly from the results reported by Trott et al. (1997; Trott et al., 1999) and Wegesin et al. (2002). In both of those studies, no right frontal effect was evident in older subjects, leading the authors to suggest that retrieval-related prefrontal activity was vulnerable to increasing age. There are many potential reasons for the discrepancy between these findings, including, for example, differences between studies in the experimental items employed, in the nature of the retrieval tasks, and possibly, in subject populations. Another possibility that should not be overlooked, however, is that the right frontal effect in the older subjects in Trott et al. (1997; Trott et al., 1999) and Wegesin et al. (2002) was, in fact, present but was obscured by overlap with the centrally distributed negative old/new effect discussed above. As has already been noted, for reasons that are unclear, this effect appears to have been distributed more bilaterally in those studies than in the present case, where its distribution was confined mainly to the left hemisphere. As is evident from Figures 3 and 4, the effect extends sufficiently far forward to give rise to a substantial negative old/new effect even at the most anterior left-hemisphere electrode. Were the effect to have been distributed bilaterally, it is clear that the positive-going frontal effect apparent over the right hemisphere would have been obscured. Resolution of this issue will likely require both more knowledge about the loci of the intracerebral generators responsible for these and other old/new effects and the application of source localization methods capable of estimating the strength of these generators as a function of age.

In summary, the present study allowed the ERP correlates of successful episodic retrieval, as operationalized in a source memory task, to be compared as a function of age while minimizing the potentially confounding effects of age-related differences in performance. The findings suggest that whereas young and older individuals may base their source decisions on different kinds of episodic information, the recovery and postretrieval monitoring of this information was supported by broadly equivalent neural mechanisms. The findings are consistent with the proposal that the primary causes of agerelated decline in episodic memory are to be found in ineffective encoding (Morcom, Good, Frackowiak, \& Rugg, 2003) or cue processing (Morcom \& Rugg, 2004), rather than in the processing of retrieved information.

\section{REFERENCES}

Burke, D. M., \& Light, L. L. (1981). Memory and aging: The role of retrieval processes. Psychological Bulletin, 90, 513-546.

CABEZA, R. (2002). Hemispheric asymmetry reduction in older adults: The HAROLD model. Psychology \& Aging, 17, 85-100.

Clegg, F., \& Warrington, E. (2000). Psychometric testing of older adults: Provisional normative data for some commonly used tests. Clinical Neuropsychological Assessment, 1, 22-37.

Coughlan, A. K., \& Hollows, S. E. (1985). The adult memory and information processing battery (AMIPB). Leeds, U.K.: St. James's University Hospital.

CraIK, F. I. M., \& McDowd, J. M. (1987). Age differences in recall and recognition. Journal of Experimental Psychology: Learning, Memory, \& Cognition, 13, 474-479.

CrAik, F. I. M., \& RABINOWITZ, J. C. (1985). The effects of presentation rate and encoding task on age-related memory deficits. Journal of Gerontology, 40, 309-315.

CURRAN, T. (2000). Brain potentials of recollection and familiarity. Memory \& Cognition, 28, 923-938.

Cycowicz, Y. M., \& FrIEDMAN, D. (2003). Source memory for the color of pictures: Event-related brain potentials (ERPs) reveal sensoryspecific retrieval-related activity. Psychophysiology, 40, 455-464.

Cycowicz, Y. M., Friedman, D., \& SnOdgrass, J. G. (2001). Remembering the color of objects: An ERP investigation of source memory. Cerebral Cortex, 11, 322-334.

Daselaar, S. M., Veltman, D. J., Rombouts, S. A., Raaijmakers, J. G. W., \& JONKER, C. (2003). Neuroanatomical correlates of episodic encoding and retrieval in young and elderly subjects. Brain, 126, 43-56.

Folstein, M. F., Folstein, S. E., \& McHugh, P. R. (1975). "Minimental state": A practical method for grading the cognitive state of patients for the clinician. Journal of Psychiatric Research, 12, 189-198.

FrIEDMAN, D. (2000). Event-related brain potential investigations of memory and aging. Biological Psychology, 54, 175-206.

Friedman, D., Berman S., \& Hamberger, M. (1993). Recognition memory and ERPs: Age-related changes in young, middle-aged and elderly adults. Journal of Psychophysiology, 7, 181-201.

Friedman, D., \& Johnson, R., JR. (2000). Event-related potential (ERP) studies of memory encoding and retrieval: A selective review. Microscopy Research \& Technique, 51, 6-28.

Glisky, E. L., Rubin, S. R., \& DAVIDSON, P. S. (2001). Source memory in older adults: An encoding or retrieval problem? Journal of Experimental Psychology: Learning, Memory, \& Cognition, 27, 1131-1146.

Grady, C. L., \& CraIK, F. I. M. (2000). Changes in memory processing with age. Current Opinion in Neurobiology, 10, 224-231.

Johansson, M., \& MECKLINGER, A. (2003). The late posterior negativity in ERP studies of episodic memory: Action monitoring and retrieval of attribute conjunctions. Biological Psychology, 64, 91-117. 
Johansson, M., Stenberg, G., Lindgren, M., \& Rosen, I. (2002). Memory for perceived and imagined pictures: An event-related potential study. Neuropsychologia, 40, 986-1002.

LaVoIE, D., \& LIGHT, L. L. (1994). Adult age differences in repetition priming: A meta-analysis. Psychology \& Aging, 9, 539-553.

LEZAK, M. D. (1995). Neuropsychological assessment. New York: Oxford University Press.

Madden, D. J., Turkington, T. G., Provenzale, J. M., Denny, L. L., Hawk, T. C., Gottlob, L. R., \& Coleman, R. E. (1999). Adult age differences in the functional neuroanatomy of verbal recognition memory. Human Brain Mapping, 7, 115-135.

MARK, R. E., \& RUGG, M. D. (1998). Age effects on brain activity associated with episodic memory retrieval: An electrophysiological study. Brain, 121, 861-873.

McCARTHY, G., \& WoOD, C. C. (1985). Scalp distributions of eventrelated potentials: An ambiguity associated with analysis of variance models. Electroencephalography \& Clinical Neurophysiology, $\mathbf{6 2}$, 203-208.

Morcom, A. M., Good, C. D., Frackowiak, R. S., \& RugG, M. D. (2003). Age effects on the neural correlates of successful memory encoding. Brain, 126, 213-229.

Morcom, A. M., \& RUGG, M. D. (2004). Effects of age on retrieval cue processing as revealed by ERPs. Neuropsychologia, 42, 1525-1542.

Nelson, H. E. (1982). The National Adult Reading Test (NART). Windsor, U.K.: NFER-Nelson.

Perfect, T. J., Williams, R. B., \& Anderton-Brown, C. (1995). Age differences in reported recollective experience are due to encoding effects, not response bias. Memory, $\mathbf{3}, 169-186$.

Raven, J. C., Raven, J., \& CoURT, J. H. (1994). Manual for Raven's progressive matrices and vocabulary. Oxford: Oxford University Press.

RUGG, M. D., \& Allan, K. (2000). Memory retrieval: An eletrophysiological perspective. In M. S. Gazzaniga (Ed.), The new cognitive neurosciences (pp. 805-816). Cambridge, MA: MIT Press.

RugG, M. D., Allan, K., \& BirCh, C. S. (2000). Electrophysiological evidence for the modulation of retrieval orientation by depth of study processing. Journal of Cognitive Neuroscience, 12, 664-678.

RugG, M. D., MARK, R. E., GIlchrist, J., \& RoBERTS, R. C. (1997). ERP repetition effects in indirect and direct tasks: Effects of age and interitem lag. Psychophysiology, 34, 572-586.

RugG, M. D., \& Morcom, A. M. (in press). The relationship between brain activity, cognitive performance and aging: The case of memory. In R. Cabeza, L. Nyberg, \& D. C. Park (Eds.), Cognitive neuroscience of aging: Linking cognitive and cerebral aging. Oxford: Oxford University Press.

Rugg, M. D., Otten, L. J., \& Henson, R. N. (2002). The neural basis of episodic memory: Evidence from functional neuroimaging. Philosophical Transactions of the Royal Society of London: Series B, 357, 1097-1110.

RugG, M. D., Schloerscheidt, A. M., \& Mark, R. E. (1998). An eletrophysiological comparison of two indices of recollection. Journal of Memory \& Language, 39, 47-69.

RUGG, M. D., \& WILDING, E. L. (2000). Retrieval processing and episodic memory. Trends in Cognitive Sciences, 4, 108-115.

RugG, M. D., \& Yonelinas, A. P. (2003). Human recognition memory: A cognitive neuroscience perspective. Trends in Cognitive Sciences, 7, 313-319.

SeñKfor, A. J., \& Van Petten, C. (1998). Who said what? An eventrelated potential investigation of source and item memory. Journal of Experimental Psychology: Learning, Memory, \& Cognition, 24, $1005-1025$

SNODGRass, J. G., \& Corwin, J. (1988). Pragmatics of measuring recognition memory: Applications to dementia and amnesia. Journal of Experimental Psychology: General, 117, 34-50.

SPENCER, W. D., \& RAZ, N. (1995). Differential effects of aging on memory for content and context: A meta-analysis. Psychology \& Aging, 10, 527-539.
Swick, D., \& KNight, R. T. (1997). Adult age differences in controlled and automatic processing. Psychology \& Aging, 12, 565-573.

Trott, C. T., Friedman, D., Ritter, W., \& Fabiani, M. (1997). Item and source memory: Differential age effects revealed by event-related potentials. NeuroReport, 8, 3373-3378.

Trott, C. T., Friedman, D., Ritter, W., Fabiani M., \& Snodgrass, J. G. (1999). Episodic priming and memory for temporal source: Event-related potentials reveal age-related differences in prefrontal functioning. Psychology \& Aging, 14, 390-413.

Tulving, E. (1983). Elements of episodic memory. Oxford: Oxford University Press.

Tulving, E. (1985). Memory and consciousness. Canadian Psychologist, 26, 1-12.

Van Petten, C., Luka, B. J., Rubin, S. R., \& Ryan, J. P. (2002). Frontal brain activity predicts individual performance in an associative memory exclusion test. Cerebral Cortex, 12, 1180-1192.

WECHSLER, D. (1987). WMS-R manual: Wechsler memory scale-revised. New York: Psychological Corporation.

Wegesin, D. J., Friedman, D., Varughese, N., \& Stern, Y. (2002). Age-related changes in source memory retrieval: An ERP replication and extension. Cognitive Brain Research, 13, 323-338.

WeST, R. L. (1996). An application of prefrontal cortex function theory to cognitive aging. Psychological Bulletin, 120, 272-292.

WILDING, E. L. (1999). Separating retrieval strategies from retrieval success: An event-related potential study of source memory. Neuropsychologia, 37, 441-454.

WILDING, E. L., \& RUGG, M. D. (1996). An event-related potential study of recognition memory with and without retrieval of source. Brain, 119, 889-905.

WILDING, E. L., \& RUGG, M. D. (1997). An event-related potential study of memory for words spoken aloud or heard. Neuropsychologia, 35, $1185-1195$.

Yonelinas, A. P. (2001). Components of episodic memory: The contribution of recollection and familiarity. Philosophical Transactions of the Royal Society of London: Series B, 356, 1363-1374.

\section{NOTES}

1. The fixation-only trials were included to maximize the comparability between this and a parallel fMRI study.

2 . Nine young subjects had a zero false alarm rate. This precluded estimation of a parametric discrimination index, such as $d^{\prime}$, or any index of response bias.

3. As is evident in Figure 4 especially, the general morphology of the waveforms from the young and the older subjects differs markedly, particularly over the frontal scalp. Similar differences have been evident in many previous studies of aging and memory, including the four cited in the present article. Since the differences represent a main effect of age and do not interact with any experimental manipulation, they are difficult to interpret (Rugg \& Morcom, in press). Whereas they might reflect functionally significant differences, they could just as easily be due to an age-related change in brain shape-for example, an alteration in generator orientation secondary to cerebral atrophy.

4. "True" source accuracy was estimated by assuming that a correct response is made when the source is recollected or, if recollection fails, when the resulting guess is correct. For a binary source judgment, the probability of a correct guess, averaged over the two judgments, is .5. Then, if $p \mathrm{~S}$ is the proportion of correct source responses and $p \mathrm{R}$ is the proportion of trials on which the source was recollected, $p \mathrm{R}=p \mathrm{~S}-$ $(1-p \mathrm{R}) / 2=2 p \mathrm{~S}-1$.

(Manuscript received December 8, 2003; revision accepted for publication March 23, 2004.) 